\title{
The use of 5-azacytidine in pregnant patient with Acute Myeloid Leukemia (AML): a case report
}

\author{
Abdullah M. Alrajhi ${ }^{1 *}$ D, Sarah A. Alhazzani ${ }^{1}$, Nouf M. Alajaji ${ }^{2}$, Fouad H. Alnajjar ${ }^{1}$, Nawal F. Alshehry ${ }^{3}$ and \\ Imran K. Tailor ${ }^{3}$
}

\begin{abstract}
Background: The management of Acute Myeloid Leukemia (AML) during pregnancy remains challenging as both the maternal and fetal outcomes should be considered. Several reports suggested that chemotherapy can be administered safely during the second and third trimester of pregnancy. However, the use of 5-azacytidine presents limitation due to lack of data.

Case presentation: A 28-years-old woman in the 26th week of gestation diagnosed with FLT3/TTD-mutated AML, complete remission was induced by Daunorubicin and Cytarabine, and subsequently with 5 -azacytidine $(75 \mathrm{mg} / \mathrm{m} 2$ daily for 7 days) with no fetal hematological or toxicity issues. Fetal ultrasound showed no aberrant morphology. Fetal size below the 5th percentile with normal umbilical artery dopplers, normal middle cerebral artery dopplers and ductus venosus doppler.

Three weeks post 5-azacytidine, the team determined the most appropriate time for delivery after balancing the risks of prematurity and prevention of disease relapse since patient in hematological remission. The patient underwent elective lower segment caesarian section and had a baby girl delivered at 35 weeks of gestation weighing $1670 \mathrm{~g}$ without apparent anomalies.

Conclusion: Treatment using 5-azacytadine during last trimester of pregnancy resulted in no major fetal and maternal complications. These findings concluded that 5-azacytadine during the third trimester of pregnancy seems to be safe however, potential risks of this agent should be considered.
\end{abstract}

Keywords: "5-azacyitidne, Acute Myeloid leukemia, pregnancy, third trimester, Daunorubicin, Cytarabine, Leukemia"

\section{Background}

AML accounts for two-thirds of all acute leukemia cases reported during pregnancy [1-3]. The incidence of leukemia during pregnancy is reported to be 1 in 75,000100,000 pregnancies. However, data regarding the management of acute myeloid leukemia (AML) during pregnancy is limited, mostly to case reports and retrospective studies, which poses difficulties in establishing parameters for optimal therapy, maternal outcome, and fetal complications [4]. The management of AML during pregnancy is complicated and remains challenging as both the maternal and fetal outcomes should be considered [1]. Administration

\footnotetext{
* Correspondence: amalrajhi@kfmc.med.sa

${ }^{1}$ Department of Pharmacy, King Fahad Medical City, Riyadh, Saudi Arabia Full list of author information is available at the end of the article
}

of chemotherapy during the first trimester of pregnancy is contraindicated due to the potential risk of teratogenicity [5]. Mothers treated in the first trimester are more likely to experience congenital malformations, spontaneous abortion, and fetal loss. However, chemotherapy can be administered safely during the second or third trimester $[6,7]$. Aviles et al. described a report of 84 children who received chemotherapy in utero including 38 during the first trimester. The children were examined for growth, physical health, development, cytogenetic, hematological, neurological, psychological, and learning disorders. All of the children observed had a normal birth weight, a normal learning and educational performance, and no congenital, neurological, or psychological abnormalities were detected [8]. Long-term follow up of children 
exposed to chemotherapy after the first trimester does not show an increased incidence of congenital malformation, preterm delivery, growth restriction, and mental disorder as compared to nonmalignant pregnant $[6,9]$. Delaying the induction of chemotherapy treatment can harmfully affect fetal growth [10]. Untreated maternal cancer can lead to adverse pregnancy outcomes, including intrauterine growth restriction (IUGR) and fetal loss [11].

There is a robust evidence regarding the safety of many chemotherapeutic agents during pregnancy. However, the use of 5-azacytidine presents limitation due to lack of data.

The purpose of this paper is to describe the treatment of AML during pregnancy with chemotherapy, including the rarely used hypomethylating agent 5-azacytidine.

\section{Case presentation}

A 28 years old lady in her 2nd pregnancy presented to the emergency department in her 26th week of gestation with dizziness and palpitation for 2 weeks. She had no prior illness and her last pregnancy was complicated by severe preeclampsia and she was delivered by caesarian section. She was found to have severe anemia with a hemoglobin of $7.2 \mathrm{~g} / \mathrm{dl}(11-16)$, WBC $57.74 \times 109 / 1$ (3.911), platelets $362 \times 109 / 1(155-435)$ with $73 \%$ circulating blasts on blood film. Renal function, liver function, echocardiogram (ECHO), and electrocardiogram (ECG) were normal. Flow cytometry on bone marrow biopsy showed $42 \%$ of total leukocytes expressed CD13, CD33, CD117, CD38, HLA-DR, MPO, CD11C partial, \& CD15 partial (27\%). Morphologically, the marrow showed $60 \%$ blasts thus confirming AML.

Cytogenetics and molecular tests confirmed the presence of Nucleophospmin 1 (NPM1) and FMS like Tyrosine Kinase 3 with Internal Tandem Duplication 3 (FLT3 ITD) (ratio of 0.22) mutation. Her fetal ultrasound has shown normal morphology, placentation and amniotic fluid but the fetal size was below the 5th percentile with normal umbilical artery dopplers, normal middle cerebral artery dopplers and ductus venosus doppler. Uterine artery dopplers were not done. She did not have prior ultrasound for comparison but was sure about her dates with regular periods. Thus, daily cardiotocography (CTG) and fetal ultrasound every 2-3 weeks to ensure proper growth were planned during her hospitalization.

Patient showed no signs of preeclampsia and was normotensive at $110 / 70 \mathrm{mmHg}$ and urine was negative for protein. She received induction chemotherapy with daunorubicin and cytarabine and achieved morphological remission on day 28 marrow (residual blasts $4 \%$ ). However, her induction was complicated by myopericarditis likely picture due to anthracyclines. She had chest pain, ST-T changes on ECG and ECHO was showing drop in the ejection fraction (EF) from 60 to $35 \%$ with regional wall motion abnormalities. Myopericarditis was managed with analgesia, beta blockers, steroids, and aspirin (aspirin was stopped later due to low platelets correlated to chemotherapy). She had an episode of febrile neutropenia during induction required admission to critical care unit, and was managed with appropriate antibiotics as per local protocol. She was frequently monitored by the maternal and fetal medicine team with fetal ultrasound every 2 weeks and CTG once daily. The fetus showed normal growth and wellbeing between scans. Post induction, she was given 5-azacytidine 75 $\mathrm{mg} / \mathrm{m} 2$ for 7 days in order to reduce morbidity due to further intensive chemotherapy such as high dose Cytarabine and secondly as a bridge to delivery. This drug was deemed by the team to be the safest option at this stage. She was given 5-azacytidine with no hematological or toxicity issues.

Three weeks post 5-azacytidine, decision was made to deliver the baby on 35 weeks of gestation to prevent disease relapse since patient was on hematological remission. She was given dexamethasone $6 \mathrm{mg}$ Intramuscularly every $12 \mathrm{~h}$ for 4 doses for lung maturity 1 week before delivery, then taken for elective lower segment caesarian section after counseling about the mode of delivery and she opted for elective cesarean section. The operation was uncomplicated and she delivered baby girl at 35 weeks of gestation weighing $1670 \mathrm{~g}$ with apgars 9 and 9 at 1 and $5 \mathrm{~min}$ and arterial cord PH 7.32. Hemoglobin level was $19 \mathrm{~g} / \mathrm{dL}$ The baby was taken to the NICU and stayed 2 weeks due to small weight for observation. ECHO was done for the baby and showed tiny PDA left to right shunt, normal left atrium and ventricle with EF of $68 \%$ and Fractional shortening (FS) of 34\%. Scheduled follow up for development was planned after 6 and 12 months. Once the patient recovered, she was given high dose cytarabine consolidation of $3 \mathrm{~g} / \mathrm{m} 2$ (planned for 3 cycles of high dose cytarabine with midostaurin).

\section{Discussion and conclusions}

We report a case of AML during pregnancy to highlight the effect of the chemotherapy, including the rarely used hypomethylating agent 5-azacytidine on the maternal and fetal outcomes. Several studies suggested that chemotherapy can be administered safely during the second and third trimester of pregnancy [6, 7]. Intrauterine growth restriction (IUGR) remains a potentially fatal complication of chemotherapy during pregnancy [12]. Cardonick and Iacobucci presented the results of 376 fetuses exposed to chemotherapy in utero and reported the following complications: IUGR (7\%), preterm labor or spontaneous rupture of membranes (5\%), fetal death (5\%) [12]. However, Fetal growth restriction observed, in this case, was prior to administrating chemotherapy. The effect of hypomethylation agents on genetic expression and fetal development, up to 
our knowledge, are limited [13]. However, this concern was disclosed with patient before proceeding with the treatment.

To our knowledge, this is the second reported case of a pregnant woman being successfully treated with 5 -azacytidine with no major fetal and maternal complications.

The first case report of 5-azacytidine treatment during pregnancy was reported by Mahdi, et al. (2016) [14]. A 39-years-old woman in the 30th week of her first pregnancy diagnosed with FLT3/ITD-mutated AML, was orally administrated sorafenib $400 \mathrm{mg}$ twice daily and subcutaneously administered 5-azacytidine $75 \mathrm{mg} / \mathrm{m}^{2} /$ day for 7 days. The patient was successfully treated with no adverse fetal outcomes that have been noted after early follow-up and a healthy newborn was delivered.

The standard regimen for remission-induction consists of a combination of anthracycline and Cytarabine [15]. This combination can be administered safely in pregnancy especially during the second or third trimesters [16]. Some anthracyclines, such as doxorubicin and daunorubicin are safer during pregnancy. Idarubicin is more lipophilic and has an increased risk of crossing the placenta with a higher rate of potential fetal complications than the other anthracyclines $[17,18]$. Therefore, idarubicin should be avoided during pregnancy.

Human data regarding the safety of 5-azacytidine during pregnancy is lacking but the safety and toxicity of 5 -azacytidine during pregnancy have been studies in both mice and rats with a dose-dependent decrease in fetal survival/ body weight, and a high incidence of microphthalmia and exencephaly $[19,20]$. 5-azacytidine was also associated with neuronal cell apoptosis in mice during the late weeks of pregnancy [21]. Data derived from animal models is, however, hard to be extrapolated to the human pregnancy; and the doses used in humans are usually far lower than those known to be teratogenic in animals [22].

In conclusion, there is insufficient data to guide practice regarding optimal therapy of AML during pregnancy. We are describing the safe treatment of AML with 5-azacytidine and in late stages of pregnancy in our case and a previously reported similar case [7]. The need for more evidence to evaluate the general safety of 5-azacytidine in early pregnancy is of paramount importance.

\section{Abbreviations}

AML: Acute myeloid leukemia; CTG: Cardiotocography; ECG: Electrocardiogram; ECHO: Echocardiogram; FS: Fractional shortening; IUGR: Intrauterine growth restriction; NPM1: Nucleophospmin 1

\section{Acknowledgements}

We would like to thank Dr. Hind AlKatan for her help in editing the manuscript prior to submission.

\section{Authors' contributions}

All authors have read and approved the manuscript. SA wrote the introduction, and discussion parts AA, IT and NFA. followed and wrote the case. NMA was responsible for writing the pregnancy part, I.T. was responsible for writing the diagnoses and treatment plan for AML and A.A. reviewed the data for accuracy. F.A., NFA. and AA reviewed and edit the manuscript.

\section{Funding}

All authors received no specific funding for this work.

\section{Availability of data and materials}

The datasets used and/or analyzed during the current case report are available from the corresponding author on reasonable request.

\section{Ethics approval and consent to participate}

N/A

Consent for publication

A written informed consent for publication was obtained.

\section{Competing interests}

The authors declare that they have no competing interests.

\section{Author details}

'Department of Pharmacy, King Fahad Medical City, Riyadh, Saudi Arabia. ${ }^{2}$ Maternal Fetal Medicine Department, King Fahad Medical City, Riyadh, Saudi Arabia. ${ }^{3}$ Comprehensive Cancer Center, King Fahad Medical City, Riyadh, Saudi Arabia.

Received: 4 August 2019 Accepted: 20 September 2019

Published online: 31 October 2019

\section{References}

1. Thomas X. Acute myeloid leukemia in the pregnant patient. Eur J Haematol. 2015. https://doi.org/10.1111/ejh.12535.

2. Jacobs IA, Chang CK, Salti GI. Coexistence of pregnancy and cancer. Am Surg. 2004;70(11):1025-9.

3. Liesveld JL, Lichtman MA. Acute myelogenous leukemia. In: Kaushansky K, Lichtman MA, Prchal, JT, Levi MM, Burns LJ, Caliguri, editors. M. Williams Hematology. 9. New York: McGraw-Hill; 2016. p. 1047-1084.

4. Abadi U, Koren G, Lishner M. Leukemia and lymphoma in pregnancy. Hematol Oncol Clin North Am. 2011;25(2):277-91 vii.

5. Oduncu FS, Kimmig R, Hepp H, Emmerich B. Cancer in pregnancy: maternalfetal conflict. J Cancer Res Clin Oncol. 2003;129(3):133-46.

6. Botha M, Rajaram S, Karunaratne K. Cancer in pregnancy. Int J Gynecol Obstet. 2018;143:137-42

7. Vandenbroucke T, Verheecke M, Fumagalli M, Lok C, Amant F. Effects of cancer treatment during pregnancy on fetal and child development. Lancet Child Adolesc Health. 2017:1(4):302-10.

8. Avilés A, Neri N. Hematological malignancies and pregnancy: a final report of 84 children who received chemotherapy in utero. Clin Lymphoma. 2001; 2(3):173-7.

9. Cardonick E, Usmani A, Ghaffar S. Perinatal outcomes of a pregnancy complicated by cancer, including neonatal follow-up after in utero exposure to chemotherapy: results of an international registry. Am J Clin Oncol. 2010; 33(3):221-8.

10. Pediatric Outcome after Maternal Cancer Diagnosed during Pregnancy. N E J Med 2016;374(7):692-693.

11. Chelghoum Y, Vey N, Raffoux E, Huguet F, Pigneux A, Witz B, et al. Acute leukemia during pregnancy. Cancer. 2005;104(1):110-7.

12. Cardonick $E$, lacobucci $A$. Use of chemotherapy during human pregnancy. Lancet Oncol. 2004;5(5):283-91.

13. Koukoura $\mathrm{O}$, Sifakis $\mathrm{S}$, Spandidos DA. DNA methylation in the human placenta and fetal growth (review). Mol Med Rep. 2012;5(4):883-9.

14. Mahdi AJ, Gosrani D, Chakraborty M, Rees A, Conner C, Wilson K, et al. Successful molecular targeted treatment of AML in pregnancy with Azacitidine and Sorafenib with no adverse fetal outcomes. Br J Haematol. 2018;180(4):603-4. 
15. Acute Myeloid Leukemia. National Comprehensive Cancer Network. (2019). (version 3.2019). Retrieved from https://www.nccn.org/professionals/ physician_gls/pdf/aml.pdf. Accessed 17 Aug 2019.

16. Fracchiolla NS, Sciumè M, Dambrosi F, Guidotti F, Ossola MW, Chidini G, et al. Acute myeloid leukemia and pregnancy: clinical experience from a single center and a review of the literature. BMC Cancer. 2017;17(1):442.

17. Matsuo K, Shimoya K, Ueda S, Wada K, Koyama M, Murata Y. Idarubicin administered during pregnancy: its effects on the fetus. Gynecol Obstet Investig. 2004;58(4):186-8.

18. Framarino-dei-malatesta M, Sammartino P, Napoli A. Does anthracyclinebased chemotherapy in pregnant women with cancer offer safe cardiac and neurodevelopmental outcomes for the developing fetus? BMC Cancer. 2017;17(1):777.

19. Cummings AM. Effect of 5-azacytidine administration during very early pregnancy. Fundam Appl Toxicol. 1994;23(3):429-33.

20. Takeuchi IK, Takeuchi YK. 5-Azacytidine-induced exencephaly in mice. J Anat. 1985;140(Pt 3):403-12.

21. Langman J, Shimada M. Cerebral cortex of the mouse after prenatal chemical insult. Am J Anat. 1971;132(3):355-74.

22. Brent RL. Utilization of animal studies to determine the effects and human risks of environmental toxicants (drugs, chemicals, and physical agents). Pediatrics. 2004:113(suppl 4):984-95.

\section{Publisher's Note}

Springer Nature remains neutral with regard to jurisdictional claims in published maps and institutional affiliations.

Ready to submit your research? Choose BMC and benefit from:

- fast, convenient online submission

- thorough peer review by experienced researchers in your field

- rapid publication on acceptance

- support for research data, including large and complex data types

- gold Open Access which fosters wider collaboration and increased citations

- maximum visibility for your research: over $100 \mathrm{M}$ website views per year

At BMC, research is always in progress.

Learn more biomedcentral.com/submissions 